\title{
Comunicação
}

[Communication]

\section{Hemograma, bioquímica sérica e histologia da biópsia hepática de bovinos após administração de polpa cítrica}

[Hemogram, serum biochemistry and hepatic histologic features in cattle after administration of citrus pulp]

\author{
N.J.F. Oliveira, M.M. Melo, L.A. Lago, E.F. Nascimento
}

\author{
Departamento de Clínica e Cirurgia Veterinárias - Escola de Veterinária - UFMG \\ Caixa Postal 567 \\ 30123-970 - Belo Horizonte, MG
}

O Brasil é o maior produtor de polpa cítrica (PC), subproduto da indústria de suco de laranja, composta por cascas, sementes e polpas de frutos cítricos (Abecitrus, 2000). O produto, empregado como substituto do milho em dietas para bovinos, apresenta elevado teor de fibra e energia, é pobre em proteína e fósforo e rico em cálcio (Grasser et al., 1995).

Em bovinos alimentados com polpa cítrica foram relatadas várias alterações clínicas, inclusive óbitos (Saunders et al., 2000; Gava, 2001) e alterações no hemograma como anemia hipocrômica discreta ou acentuada (Vasconcelos et al., 1999; Gava, 2001).

Este estudo teve como objetivo a avaliação semanal do hemograma, do perfil bioquímico sérico (fosfatase alcalina, aspartato aminotransferase, gama glutamiltransferase, uréia, creatinina, cálcio e fósforo) e do exame microscópico de fragmentos de fígado em bovinos alimentados com dieta contendo $40 \%$ de PC durante 43 dias.

Foram utilizados cinco bovinos mestiços com peso médio de $150 \mathrm{~kg}$. Quinze dias antes da administração da polpa cítrica foram feitas três coletas de sangue $\left(1^{\circ}, 7^{\circ}\right.$ e $15^{\circ}$ dias $)$, em tubos de vidro (com e sem $0,1 \mathrm{ml}$ de EDTA a $10 \%$ ), para a realização do hemograma e do perfil bioquímico sérico, sendo a média dos valores desses exames

Recebido para publicação em 10 de maio de 2004

Recebido para publicação, após modificações, em 15 de fevereiro de 2005

E-mail: marília@vet.ufmg.br considerada como valor padrão do início do experimento (tempo zero).

A PC (40\% da ingestão de matéria seca - IMS) oferecida em mistura completa com feno de $B$. brizantha e farelo de soja tostado (Nutrient..., 1984) foi oferecida aos animais após adaptação por 15 dias à dieta. Cada novilha recebeu, em média, 2,0kg de $\mathrm{PC} /$ dia, durante 30 dias. Os hemogramas e dosagens bioquímicas séricas foram realizados aos 8, 15, 22, 29, 36 e 43 dias.

O número de eritrócitos e de leucócitos totais foi determinado pela contagem em câmara de Neubauer, e o volume globular (VG) foi medido pelo método do microhematócrito (Ferreira Neto et al., 1978). A concentração de hemoglobina (Hb) foi determinada pelo método colorimétrico da cianometahemoglobina (Kampen e Zijlstra, 1963). A contagem diferencial de leucócitos foi feita em esfregaços fixados e corados pelo método de May-Grunwald-Giemsa (Ferreira Neto et al., 1978). As dosagens bioquímicas séricas de proteína total (PT), aspartato aminotransferase (AST), fosfatase alcalina (FA), uréia, creatinina, cálcio e fósforo foram feitas pelo método colorimétrico, com kits comerciais ${ }^{1}$. A enzima sérica gama glutamiltransferase (GGT) foi estimada pelo método de fotometria por reflectância ${ }^{2}$ somente na última colheita (43 dias). As coletas de fragmentos hepáticos foram realizadas antes e depois (43 dias) do

\footnotetext{
${ }^{1}$ Labtest, Bioclin $®$

${ }^{2}$ Reflotron, Boehringer-Mannehein ${ }^{\circledR}$
} 
fornecimento da dieta com $40 \%$ de PC, pela técnica de biópsia percutânea cega (Kampl et al., 1995) e os fragmentos hepáticos foram fixados, processados e corados pela técnica da hematoxilina-eosina (Luna, 1968).

O experimento foi delineado em blocos ao acaso, em que cada indivíduo foi seu próprio controle. Os dados foram analisados pelo programa Statistical Analysis System (Users's..., 1985) e as médias foram comparadas utilizando-se o teste Student-Newman-Keuls com $\mathrm{P} \leq 0,05$ (Sampaio, 1998).

Os bovinos apresentaram perfil hematológico sem alterações (Tab. 1 e 2). A PT aumentou de $6,39 \mathrm{~g} / \mathrm{dl}$ (tempo zero) para $8,01 \mathrm{~g} / \mathrm{dl}(\mathrm{P} \leq 0,05)$ ao final do experimento. A enzima AST variou entre 15 e 24UI/l, mas as diferenças não foram significativas. O valor médio de GGT foi de $9,18 \mathrm{UI} / 1$ para o grupo ao final do experimento. A FA apresentou elevação $(\mathrm{P} \leq 0,05)$ de 46,15 para 190UI/1 (Tab. 3). A uréia e a creatinina não apresentaram alterações significativas, permanecendo entre 17 e 27 e 1,4 e $1,6 \mathrm{mg} / \mathrm{dl}$, respectivamente. $O$ cálcio sérico variou de 7,20 a $9,64 \mathrm{mg} / \mathrm{dl}$, com aumento significativo já na primeira semana da adaptação. Houve redução expressiva do fósforo na primeira semana de adaptação à dieta, com tendência a elevar um pouco nas semanas posteriores, sem atingir o valor do tempo zero, sugerindo hipofosfatemia.

O exame microscópico dos fragmentos hepáticos não revelou alterações dignas de nota.

Os animais apresentaram hemograma com valores normais para a espécie (Tab.1 e 2) já relatado por Fagliari et al. (1998). Houve aumento sérico da PT, sem variação no VG. Esse aumento fisiológico foi causado pela dieta com teor de proteína bruta balanceado (Tennant, 1997), pois os animais não apresentaram nem anemia nem desidratação.

O perfil enzimático hepático foi demonstrado pelos valores séricos de AST e GGT (Tab. 3), que permaneceram dentro dos limites normais para bovinos segundo Roussel et al. (1997a e b), indicando que os animais não apresentavam doença hepatobiliar, confirmada pela ausência de lesões na microscopia hepática.

Galhardo et al. (1997) verificaram elevação sérica de AST em bovinos alimentados com PC contendo diacetoxiscirpenol e Griffiths e Done (1991), elevação da GGT sérica em bovinos alimentados com PC contaminada por citrinina. Portanto, os aumentos de AST e GGT em bovinos estão associados à contaminação da polpa cítrica com micotoxinas.

A concentração de FA aumentou $(\mathrm{P} \leq 0,05)$ após a administração de polpa cítrica. Os resultados estão acima dos valores descritos em bovinos, no Brasil por Fagliari et al. (1998) e Morais et al. (2000a). Provavelmente o aumento verificado se seja deveu à isoenzima óssea, pois como foi relatado anteriormente, os animais apresentaram valores das enzimas AST e GGT dentro dos limites normais. Apesar do normalmente elevado coeficiente de variação (CV), neste delineamento ele foi de $14,4 \%$, menor do que o encontrado por Morais et al., (2000a), 27,8\%.

A uréia sérica apresentou-se dentro dos valores normais relatados por Roussel et al. (1997a e b) e Fagliari et al. (1998). Apesar de não ter havido aumento significativo após administração da polpa cítrica, percebe-se aumento da uréia sérica sem aumento de creatinina. Essa foi uma elevação fisiológica e de origem pré-renal (Finco, 1997), indicando maior ingestão protéica.

Não houve alterações nos valores séricos de creatinina, obtendo-se valores semelhante aos valores descritos para bovinos sadios por Roussel et al., (1997a e b); Fagliari et al. (1998); e Morais et al. (2000a). A creatinina, a partir da reação da creatina para formar fosfocreatina muscular, constitui um indicativo da função renal e é somente filtrada e não reabsorvida pelos rins. A creatinina não está associada à alimentação do animal como a uréia, descrita anteriormente. As dosagens de uréia e creatinina séricas, indicadas no controle da função renal, revelaram que a polpa cítrica administrada por 43 dias não foi capaz de causar alterações renais. 
Tabela 1. Variação temporal do número de eritrócitos $\left(10^{6} / \mathrm{mm}^{3}\right)$, volume globular (VG - \%), hemoglobina ( $\mathrm{Hb}-\mathrm{g} / \mathrm{dl})$, volume globular médio (VGM - fl), hemoglobina globular média (HGM - pg), concentração de hemoglobina globular média (CHGM - \%) e proteína total (PT - g/dl) em bovinos após administração de dieta contendo $40 \%$ de polpa cítrica em diferentes tempos

\begin{tabular}{lccccccc} 
Dia & $\begin{array}{c}\text { Eritrócitos } \\
\left(10^{6} / \mathrm{mm}^{3}\right)\end{array}$ & $\begin{array}{c}\text { VG } \\
(\%)\end{array}$ & $\begin{array}{c}\text { Hb } \\
(\mathrm{g} / \mathrm{dl})\end{array}$ & $\begin{array}{c}\text { VGM } \\
(\mathrm{fl})\end{array}$ & $\begin{array}{c}\text { HGM } \\
(\mathrm{pg})\end{array}$ & $\begin{array}{c}\text { CHGM } \\
(\%)\end{array}$ & $\begin{array}{c}\text { PT } \\
(\mathrm{g} / \mathrm{dl})\end{array}$ \\
\hline 0 & $9,214 \mathrm{a}$ & $38,0 \mathrm{a}$ & $12,75 \mathrm{ab}$ & $39,51 \mathrm{a}$ & $14,32 \mathrm{a}$ & $33,81 \mathrm{a}$ & $6,39 \mathrm{c}$ \\
8 & $8,300 \mathrm{a}$ & $36,2 \mathrm{a}$ & $11,96 \mathrm{~b}$ & $43,91 \mathrm{a}$ & $14,53 \mathrm{a}$ & $33,12 \mathrm{a}$ & $6,88 \mathrm{bc}$ \\
15 & $9,360 \mathrm{a}$ & $36,4 \mathrm{a}$ & $12,11 \mathrm{~b}$ & $38,97 \mathrm{a}$ & $12,96 \mathrm{a}$ & $33,19 \mathrm{a}$ & $7,52 \mathrm{ab}$ \\
22 & $8,940 \mathrm{a}$ & $38,8 \mathrm{a}$ & $13,19 \mathrm{ab}$ & $43,47 \mathrm{a}$ & $15,18 \mathrm{a}$ & $34,05 \mathrm{a}$ & $7,37 \mathrm{ab}$ \\
29 & $9,180 \mathrm{a}$ & $36,6 \mathrm{a}$ & $11,98 \mathrm{~b}$ & $39,93 \mathrm{a}$ & $13,06 \mathrm{a}$ & $32,71 \mathrm{a}$ & $7,31 \mathrm{ab}$ \\
36 & $9,560 \mathrm{a}$ & $39,6 \mathrm{a}$ & $13,57 \mathrm{a}$ & $41,47 \mathrm{a}$ & $14,22 \mathrm{a}$ & $34,34 \mathrm{a}$ & $7,67 \mathrm{ab}$ \\
43 & $9,460 \mathrm{a}$ & $39,2 \mathrm{a}$ & $12,79 \mathrm{ab}$ & $41,61 \mathrm{a}$ & $13,57 \mathrm{a}$ & $33,01 \mathrm{a}$ & $8,01 \mathrm{a}$ \\
$\mathrm{CV} \mathrm{( \% )}$ & 8,65 & 5,65 & 6,14 & 10,26 & 8,09 & 3,53 & 7,52 \\
\hline
\end{tabular}

Valores com letras distintas na coluna diferem entre si pelo teste $\mathrm{SNK}(\mathrm{P} \leq 0,05)$.

Tabela 2. Variação temporal do número de leucócitos, neutrófilos bastonetes e segmentados, linfócitos, monócitos e eosinófilos $/ \mathrm{mm}^{3}$ de sangue em bovinos após administração de dieta contendo $40 \%$ de polpa cítrica em diferentes tempos

\begin{tabular}{lcccccc}
\hline Dia & $\begin{array}{c}\text { Leucócitos } \\
\text { totais/ } \mathrm{mm}^{3}\end{array}$ & $\begin{array}{c}\text { Neutrófilos } \\
\text { bastonetes } / \mathrm{mm}^{3}\end{array}$ & $\begin{array}{c}\text { Neutrófilos } \\
\text { segmentados } / \mathrm{mm}^{3}\end{array}$ & $\begin{array}{c}\text { Linfócitos/ } \\
\mathrm{mm}^{3}\end{array}$ & $\begin{array}{c}\text { Monócitos/ } \\
\mathrm{mm}^{3}\end{array}$ & $\begin{array}{c}\text { Eosinófilos/ } \\
\mathrm{mm}^{3}\end{array}$ \\
\hline 0 & $10.206 \mathrm{a}^{*}$ & $140,8 \mathrm{a}$ & $2100 \mathrm{a}$ & $6953 \mathrm{a}$ & $400,0 \mathrm{a}$ & $135,0 \mathrm{a}$ \\
8 & $9.760 \mathrm{a}$ & $80,0 \mathrm{a}$ & $2371 \mathrm{a}$ & $7349 \mathrm{a}$ & $328,6 \mathrm{a}$ & $332,0 \mathrm{a}$ \\
15 & $11.070 \mathrm{a}$ & $69,6 \mathrm{a}$ & $2811 \mathrm{a}$ & $7546 \mathrm{a}$ & $427,8 \mathrm{a}$ & $197,4 \mathrm{a}$ \\
22 & $9.680 \mathrm{a}$ & $64,0 \mathrm{a}$ & $2032 \mathrm{a}$ & $6985 \mathrm{a}$ & $341,2 \mathrm{a}$ & $257,4 \mathrm{a}$ \\
29 & $11.100 \mathrm{a}$ & $150,6 \mathrm{a}$ & $2512 \mathrm{a}$ & $8063 \mathrm{a}$ & $121,8 \mathrm{a}$ & $252,8 \mathrm{a}$ \\
36 & $10.956 \mathrm{a}$ & $33,0 \mathrm{a}$ & $2227 \mathrm{a}$ & $8521 \mathrm{a}$ & $330,0 \mathrm{a}$ & $232,2 \mathrm{a}$ \\
43 & $12.360 \mathrm{a}$ & $110,6 \mathrm{a}$ & $2700 \mathrm{a}$ & $9255 \mathrm{a}$ & $221,4 \mathrm{a}$ & $183,8 \mathrm{a}$ \\
$\mathrm{CV} \%$ & 19,89 & 96,72 & 31,84 & 20,38 & 69,46 & 65,32 \\
\hline
\end{tabular}

Valores com letras distintas na coluna diferem entre si pelo teste $\mathrm{SNK}(\mathrm{P} \leq 0,05)$.

Tabela 3. Variação temporal das enzimas (UI/l) aspartato aminotransferase e fosfatase alcalina e dos constituintes séricos $(\mathrm{mg} / \mathrm{dl})$ uréia, creatinina, cálcio e fósforo em bovinos, após administração de dieta contendo $40 \%$ de polpa cítrica nos diferentes tempos

\begin{tabular}{lcccccc}
\hline Dia & $\begin{array}{c}\text { Aspartato } \\
\text { aminotransferase (UI/l) }\end{array}$ & $\begin{array}{c}\text { Fosfatase alcalina } \\
(\mathrm{UI} / \mathrm{l})\end{array}$ & $\begin{array}{c}\text { Uréia } \\
(\mathrm{mg} / \mathrm{dl})\end{array}$ & $\begin{array}{c}\text { Creatinina } \\
(\mathrm{mg} / \mathrm{dl})\end{array}$ & $\begin{array}{c}\text { Cálcio } \\
(\mathrm{mg} / \mathrm{dl})\end{array}$ & $\begin{array}{c}\text { Fósforo } \\
(\mathrm{mg} / \mathrm{dl})\end{array}$ \\
\hline 0 & $14,65 \mathrm{a}$ & $46,15 \mathrm{~d}$ & $16,98 \mathrm{a}$ & $1,63 \mathrm{a}$ & $7,20 \mathrm{~b}$ & $6,42 \mathrm{a}$ \\
8 & $15,62 \mathrm{a}$ & $80,81 \mathrm{c}$ & $23,94 \mathrm{a}$ & $1,63 \mathrm{a}$ & $9,64 \mathrm{a}$ & $3,97 \mathrm{~b}$ \\
15 & $17,35 \mathrm{a}$ & $102,82 \mathrm{c}$ & $23,82 \mathrm{a}$ & $1,44 \mathrm{a}$ & $7,87 \mathrm{ab}$ & $3,83 \mathrm{~b}$ \\
22 & $21,49 \mathrm{a}$ & $126,93 \mathrm{~b}$ & $25,40 \mathrm{a}$ & $1,42 \mathrm{a}$ & $7,89 \mathrm{ab}$ & $3,26 \mathrm{~b}$ \\
29 & $20,73 \mathrm{a}$ & $138,38 \mathrm{~b}$ & $24,97 \mathrm{a}$ & $1,55 \mathrm{a}$ & $7,31 \mathrm{~b}$ & $4,92 \mathrm{~b}$ \\
36 & $20,24 \mathrm{a}$ & $177,60 \mathrm{a}$ & $26,71 \mathrm{a}$ & $1,44 \mathrm{a}$ & $7,93 \mathrm{ab}$ & $4,15 \mathrm{~b}$ \\
43 & $24,10 \mathrm{a}$ & $190,02 \mathrm{a}$ & $24,49 \mathrm{a}$ & $1,48 \mathrm{a}$ & $9,54 \mathrm{a}$ & $4,59 \mathrm{~b}$ \\
CV $(\%)$ & 12,62 & 14,39 & 21,92 & 8,81 & 2,52 & 20,42 \\
\hline
\end{tabular}

Valores com letras distintas na coluna diferem entre si pelo teste SNK $(\mathrm{P} \leq 0,05)$.

O aumento do cálcio sérico ocorrido aos oito dias após a administração da polpa cítrica assim se manteve até 22 dias, diminuiu aos 29 dias e apresentou novo aumento aos 43 dias. Essas alterações não ultrapassaram os valores de referência para a espécie bovina. Todos eles situaram-se dentro dos limites de referência citados por Morais et al. (2000b). Considerando apenas o fornecimento de cálcio da $\mathrm{PC}$ e da mistura mineral, com consumo médio estimado em 50g/dia, os animais receberam aproximadamente $24 \mathrm{~g}$ de cálcio/dia, suficiente para satisfazer o requisito de $17,9 \mathrm{~g}$.

As médias de fósforo sérico (Tab. 3), exceto a do tempo zero, situaram-se abaixo dos limites mínimos propostos por Morais et al. (2000b), indicando que a dieta provocou redução $(\mathrm{P} \leq 0,05)$ 
no fósforo sérico a partir da administração da dieta com PC.

Mesmo recebendo mistura mineral a vontade, os resultados evidenciaram desequilíbrio mineral, constatado pela elevação do cálcio sérico e hipofosfatemia. A dieta com $40 \%$ de PC, caracteristicamente pobre em fósforo e rica em cálcio, provocou alterações nos níveis séricos desses elementos.

A biópsia hepática, de fácil execução segundo técnica de Kampl et al. (1995), foi bem tolerada pelos bovinos. O perfil histológico dos fragmentos do fígado foi considerado normal ao final do período. Associado aos resultados normais de AST e GGT, permite suspeitar que o aumento de FA sérica seja provocado por desequilíbrio mineral, justificado pela elevação significativa do cálcio sérico $(\mathrm{P} \leq 0,05)$ e hipofosfatemia. A atividade sérica da FA em bovinos é determinada principalmente pela isoenzima de origem óssea (Tennant, 1997), portanto, o desequilíbrio mineral provocaria alterações no metabolismo ósseo, justificando a elevação de FA sérica.

Palavras-chave: bovino, polpa cítrica, hemograma, bioquímica sérica, histologia hepática

\begin{abstract}
Hemogram and serum biochemistry (aspartate aminotransferase, alkaline phosphatase and gamma glutamiltransferase, total protein, urea, creatinine, calcium and phosphorus) were performed weekly in five crossbreed bovine after consumption of a diet containing citrus pulp pellets (40\%), for 43 days. Percutaneous hepatic biopsy and histologic evaluation were performed in each animal before and after consumption of the citrus pulp diet. Hemogram, the enzymes aspartate aminotransferase and gamma glutamiltransferase, urea and creatinine had normal levels at the end of the experiment. No histologic lesions were observed in liver samples before or after citrus pulp consumption. However, there was an increase of serum phosphorus and reduction of serum calcium ( $\leq \leq 0.05)$, without hypercalcemia, after consumption of citrus pulp diet. There was also an increase in serum alkaline phosphatase ( $p \leq 0.05)$, probably induced by bone isoenzyme.
\end{abstract}

Keywords: cattle, citrus pulp, hemogram, serum biochemistry, hepatic histology

\section{REFERÊNCIAS BIBLIOGRÁFICAS}

ABECITRUS. Associação Brasileira dos Exportadores de Cítricos. Subprodutos da laranja. Disponível em: <http://www.abecitrus. com.br>. Acessado em: 23 fev. 2000.

FAGLIARI, J.J.; SANTANA. A.E.; LUCAS, F.A. Constituintes sangüíneos de bovinos lactentes, desmamados e adultos das raças Nelore (Bos indicus) e Holandesa (Bos taurus) e de bubalinos (Bubalus bubalis) da raça Murrah. Arq. Bras. Med. Vet. Zootec., v.50, p.263-271, 1998.

FERREIRA NETO, J.M.; VIANA, E.S.; MAGALHÃES, L.M. Patologia clínica veterinária. Belo Horizonte: Rabelo e Brasil, 1978. 279p.

FINCO, R.D. Kidney function. In: KANEKO,
J.J.; HARVEY, J.W.; BRUSS, M.L. (Eds.) Clinical biochemistry of domestic animals. 5.ed. San Diego: Academic, 1997. cap.17, p.441-484.

GALHARDO, M., BIRGEL Jr., E.H., SOARES, L.M. et al. Poisoning by Diacetocyscirpenol in cattle fed citrus pulp in the state of São Paulo, Brazil. Braz. J. Vet. Res. Anim. Sci., v.32, p.9091, 1997.

GAVA, A. Intoxicação por polpa cítrica em bovinos. In: MULUCELLI, B.E. (Organizador). ENCONTRO NACIONAL DE PATOLOGIA VETERINÁRIA - Resumos. Pirassununga: Fundação de Estudos e Pesquisas em Agronomia, Medicina Veterinária e Zootecnia, 2001. P. 269-270.

GRASSER, L.A.; FADEL, J.G.; GARNETT, I. et al. Quantitative and economic importance of nine selected by-products used in California 
dairy rations. J. Dairy Sci., v.78, .962-971, 1995.

GRIFFITHS, I.B.; DONE, S.H. Citrinin as a possible cause of pruritis, pirexia and haemorragic sindrome in cattle. Vet. Rec., v.129, p.113-117, 1991.

KAMPEN, E.J.; ZIILSTRA, W.G. Standardization of haemaglobinometry. In: Erythrocytometric methods and their standardization. CONGRESS OF EUROPEAN SOCIETY OF HAEMATOLOGY, 9., Lisbon, 1963. Proceedings... Basel: S. Karger, 1964. p.68-72.

KAMPL, B.; ZDELAR, F.; MARTINCIC, T. et al. Our experience with liver biopsy in dairy cattle. Vet. Arhiv., v.65, p.63-67, 1995.

LUNA, L.G. Manual of histologic staining methods of the Armed Forces Institute of Pathology. 3.ed. New York: McGraw Hill, 1968.

MORAIS, M.G.; GONÇALVES, L.C.; LOPES, H.O.S. et al. Variação sazonal de eletrólitos no sangue de vacas aneloradas sob pastejo contínuo de Brachiaria decumbens. Arq. Bras. Med. Vet. Zootec., v.52, p.105-110, 2000b.

MORAIS, M.G.; RANGEL, J.M.; MADUREIRA, J.S. et al. Variação sazonal da bioquímica clínica de vacas aneloradas sob pastejo contínuo de Brachiaria decumbens. Arq. Bras. Med. Vet. Zootec., v.52, p.98-104, 2000a.

NICOLETTI, J.L.M.; KOHAYAGAWA, A.; GANDOLFI, W. Alguns teores de constituintes séricos e hemograma em vacas da raça Gir, Holandês Preto e Branco e Mestiças (Girolanda) na região de Botucatu- SP. Arq. Esc. Vet. UFMG, v.33, p.19-30, 1981.

NUTRIENT requirements of beef cattle. 6.ed. Washington: NRC, 1984. 90p.

ROUSSEL, A.J.; WHITNEY, M.S.; COLE, D.J. Interpreting a bovine serum chemistry profile: part1. Vet. Med., v.92, p.553-558, 1997a.

ROUSSEL, A.J.; WHITNEY, M.S.; COLE, D.J. Interpreting a bovine serum chemistry profile: part 2. Vet. Med., v.92, p.559-566, 1997 b.

SAMPAIO, I.B.M. Estatística aplicada à experimentação animal. Belo Horizonte: Fundação de Ensino e Pesquisa em Medicina Veterinária e Zootecnia, 1998, 221p.

SAUNDERS, G.K.; BLODGET, D.J.; HUTCHINS, T.A. et al. Suspected citrus pulp toxicosis in dairy cattle. J. Vet. Diagn. Invest., v.12, p.269-271, 2000.

TENNANT, B.C. Hepatic function. In: KANEKO, J.J.; HARVEY , J.W.; BRUSS, M.L. (Eds.) Clinical biochemistry of domestic animals. 5.ed. San Diego: Academic, 1997. Cap.13, p.327-352.

USER'S guide: Statistics. 5.ed. Cary, NC SAS Institute, 1985, v.1, 956p.

VASCONCELOS, R.O.; DUTRA, I.S.; ALESSI, A.C. et al. Intoxicação por polpa cítrica em vacas leiteiras. In: NUNES, I.J. (Ed.). ENCONTRO NACIONAL DE PATOLOGIA VETERINÁRIA

- Resumos. Belo Horizonte: Fundação de Ensino e Pesquisa- Medicina Veterinária e Zootecnia, 1999. p.14. 